\title{
Change of paradigm or change of heart?
}

\author{
David L. Joyce, MD
}

\author{
From the Department of Cardiovascular Surgery, Mayo Clinic, Rochester, Minn \\ Disclosures: Author has nothing to disclose with regard to commercial support. \\ Received for publication March 13, 2017; accepted for publication March 17, 2017; available ahead of print April \\ $12,2017$. \\ Address for reprints: David L. Joyce, MD, Department of Cardiovascular Surgery, Mayo Clinic, 200 First St SW, \\ Rochester, MN 55905 (E-mail: djoyce4@gmail.com). \\ J Thorac Cardiovasc Surg 2017;154:515-6 \\ 0022-5223/ $\$ 36.00$ \\ Copyright (C 2017 by The American Association for Thoracic Surgery \\ http://dx.doi.org/10.1016/j.jtcvs.2017.03.066
}

In their article in this issue of the Journal, "High-risk Cardiac Surgery as an Alternative to Transplant or Mechanical Support in Patients With End-Stage Heart Failure," Kawajiri and colleagues ${ }^{1}$ address a clinical scenario that has now become a relatively common dilemma in coronary care units throughout the world. The typical patient is 68 years old with New York Heart Association class IIIB to IV symptoms, severe multivessel coronary artery disease, a dilated ventricle, moderate mitral regurgitation, and atrial fibrillation. Cardiomyopathy with an ejection fraction of around $15 \%$, chronic renal insufficiency with a creatinine level of around $1.5 \mathrm{mg} / \mathrm{dL}$, and chronic obstructive pulmonary disease are typically involved, along with questionable viability and target quality. Most surgeons would agree that this patient would be best served with an operation-ideally performed by a colleague during their own week of vacation. Things become a bit more complicated when one begins to consider just what type of surgery one should perform.

Advanced heart failure therapies have made tremendous strides during the past 15 years, and there is a temptation in a scenario like this to move directly to a left ventricular assist device (LVAD) strategy because of the well-known adage that mortality and ejection fraction tend to shake hands at around $15 \%$ in the setting of conventional surgery. Indeed, a review of the 30-day mortality in the Randomized Olmesartan And Diabetes MicroAlbuminuria Prevention (ROADMAP) trial for LVAD therapy compares very favorably at $1 \%{ }^{2}$ with the Surgical Treatment for Ischemic Heart Failure (STICH) trial rate of $4 \%$ after coronary artery bypass grafting. ${ }^{3}$ Nevertheless, meaningful long-term comparisons are confounded by the fact that patients enrolled in LVAD trials are uniformly dissimilar to those enrolled in conventional surgery studies, with minimal data available for patients with LVAD support beyond 2 years. Kawajiri and colleagues ${ }^{1}$ have very effectively parsed out many of these confounders in a way that allows for a better understanding of the long-term outcomes of these patients according to transplant eligibility and type of therapy rendered.

By selecting out patients with a maximum oxygen uptake less than $14 \mathrm{~mL} / \mathrm{kg} / \mathrm{min}$ and ejection fraction less than $20 \%$,

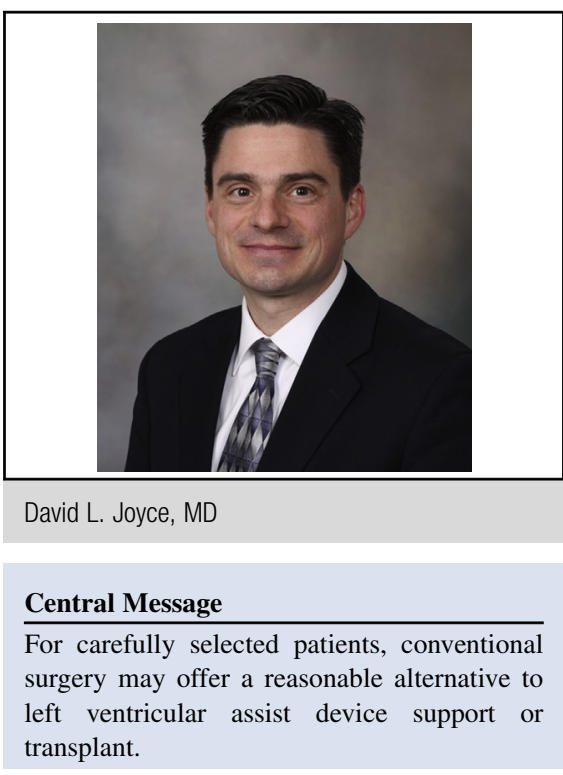

See Article page 517.

Kawajiri and colleagues ${ }^{1}$ have identified a patient population that would present significant risks for conventional surgery while at the same time qualifying for consideration of advanced heart failure therapies. An intriguing observation is the fact that isolated coronary artery bypass grafting procedures were associated with a reasonable $2.3 \%$ inhospital mortality, whereas those who underwent concomitant procedures had a $14.3 \%$ mortality. These findings seem to support a number of other studies that advocate for a "less is more" approach to these challenging patients. 4 An obvious limitation of this study is the bias introduced by the fact that patients had already been selected for conventional surgery at the time of inclusion. In addition, the patient population is also somewhat heterogeneous in terms of heart failure etiology (although predominantly ischemic), which limits the applicability of the results. Nevertheless, these data provide an excellent framework and an additional dimension for selection conference discussions surrounding these complex patients. Clearly, this represents an area that is fertile for further study, particularly as the evolution of LVAD technology continues to move the goalposts with respect to improved long-term outcomes.

\section{References}

1. Kawajiri H, Manlhiot C, Ross H, Delgado D, Billia F, McDonald M, et al. Highrisk cardiac surgery as an alternative to transplant or mechanical support in patients with end-stage heart failure. J Thorac Cardiovasc Surg. 2017;154:517-25. 
2. Estep JD, Starling RC, Horstmanshof DA, Milano CA, Selzman CH, Shah KB, et al; ROADMAP Study Investigators. Risk assessment and comparative effectiveness of left ventricular assist device and medical management in ambulatory heart failure patients: results from the ROADMAP Study. J Am Coll Cardiol. 2015;66:1747-61.

3. Velazquez EJ, Lee KL, Deja MA, Jain A, Sopko G, Marchenko A, et al; STICH Investigators. Coronary-artery bypass surgery in patients with left ventricular dysfunction. N Engl J Med. 2011;364:1607-16.
4. Michler RE, Smith PK, Parides MK, Ailawadi G, Thourani V, Moskowitz AJ, et al; CTSN. Two-year outcomes of surgical treatment of moderate ischemic mitral regurgitation. N Engl J Med. 2016;374:1932-41.

5. Smith PK, Puskas JD, Ascheim DD, Voisine P, Gelijns AC, Moskowitz AJ, et al. Cardiothoracic Surgical Trials Network Investigators. Surgical treatment of moderate ischemic mitral regurgitation. $N$ Engl J Med. 2014;371: 2178-88. 